\title{
Market-based instruments and technology choices: a synthesis
}

\author{
Raphael Calel
}

August 2011

Centre for Climate Change Economics and Policy Working Paper No. 66

Grantham Research Institute on Climate Change and the Environment Working Paper No. 57 
The Centre for Climate Change Economics and Policy (CCCEP) was established by the University of Leeds and the London School of Economics and Political Science in 2008 to advance public and private action on climate change through innovative, rigorous research. The Centre is funded by the UK Economic and Social Research Council and has five inter-linked research programmes:

1. Developing climate science and economics

2. Climate change governance for a new global deal

3. Adaptation to climate change and human development

4. Governments, markets and climate change mitigation

5. The Munich Re Programme - Evaluating the economics of climate risks and opportunities in the insurance sector

More information about the Centre for Climate Change Economics and Policy can be found at: http://www.cccep.ac.uk.

The Grantham Research Institute on Climate Change and the Environment was established by the London School of Economics and Political Science in 2008 to bring together international expertise on economics, finance, geography, the environment, international development and political economy to create a worldleading centre for policy-relevant research and training in climate change and the environment. The Institute is funded by the Grantham Foundation for the Protection of the Environment, and has five research programmes:

1. Use of climate science in decision-making

2. Mitigation of climate change (including the roles of carbon markets and lowcarbon technologies)

3. Impacts of, and adaptation to, climate change, and its effects on development

4. Governance of climate change

5. Management of forests and ecosystems

More information about the Grantham Research Institute on Climate Change and the Environment can be found at: http://www.lse.ac.uk/grantham.

This working paper is intended to stimulate discussion within the research community and among users of research, and its content may have been submitted for publication in academic journals. It has been reviewed by at least one internal referee before publication. The views expressed in this paper represent those of the author(s) and do not necessarily represent those of the host institutions or funders. 


\title{
Market-based Instruments and Technology Choices: A Synthesis*
}

\author{
Raphael Calel ${ }^{\dagger}$ \\ Grantham Research Institute on Climate Change and the Environment, London School of \\ Economics and Political Science, London, UK
}

August 2011

\begin{abstract}
Market-based instruments are widely used to encourage innovation and investment in cleaner technologies. Using a simple analytical framework and graphical representations, this paper provides a theoretical synthesis of the relationship between emissions prices/taxes and the firm's optimal technology choice. This unified treatment incorporates the insights of a wide theoretical literature, as well as providing several new findings. Most surprisingly, perhaps, we identify circumstances in which a higher price of emissions actually reduces the incentive for investment in abatement technologies. We discuss the implications for environmental policy. The main conclusion is that a price on emissions invariably affects the type of abatement technologies firms invest in, so that the technological side of emissions abatement must always be considered in tandem with the design of the market-based instrument itself.
\end{abstract}

\section{Introduction}

Market-based instruments - emissions taxes and tradable emissions permits - are widely used to encourage emissions abatement for a range of pollutants. World-wide, they account for hundreds of billions of dollars in government revenues and traded value each

\footnotetext{
*I am grateful to Sam Fankhauser, Carmen Marchiori, and Luca Taschini for helpful comments and suggestions on earlier drafts. I would also like to acknowledge the financial support of the ESRC, the Jan Wallander and Tom Hedelius Foundation, and the Grantham Foundation.

${ }^{\dagger}$ Corresponding author: r.calel@lse.ac.uk
} 
year. These market-based instruments are already playing a central role in climate policy, and are expected to play an even greater role in the future. The ability of these instruments to encourage abatement through innovation and investment in clean technologies is likely the single most important measure of their success or failure, since this type of abatement reduces the long-run cost of achieving ambitious emissions reductions targets (Kneese and Schultze, 1975). So what is the relationship between market-based instruments and firms' technology choices?

Underpinning the now growing empirical literature on this question (see Popp et al., 2009, Popp, 2010, and Ambec et al., 2010, for recent surveys) is an extensive theoretical literature. The theoretical literature compares the incentives for investment under permits and taxes (Malueg, 1989; Fischer et al., 2003; Weber and Neuhoff, 2010), tries to model the properties of different technologies (Bauman et al., 2008), asks what effect market power (Montero, 2002a,b) or the credibility of the regulator (Kennedy and Laplante, 1995, 1999; Mash et al., 2003; Requate, 2005) might have on these incentives, and much more. This paper presents a simple model that incorporates these and many more contributions to this literature into one unified analytical framework. Apart from synthesizing the theoretical literature, the unified treatment also provides several new insights about the relationship between market-based instruments and firms' technology choices. Most surprisingly, perhaps, we identify circumstances in which a higher price of emissions actually reduces the incentive for investment in cleaner technologies.

Section 2 introduces a simple model of technology choice in both algebraic and graphical forms. Although we will refer back to the mathematical model throughout, we rely mainly on graphs to communicate the conclusions of the analysis. Section 3 extends the technology choice problem to situations when the firm's expectations about competitor and regulatory responses are more complex, such as when firms have market power, when they can affect the diffusion of their innovations, and when the regulator cannot commit to a future policy. Section 4 concludes.

\section{Market-based instruments and technology choices}

\subsection{The model}

Let us first set out a simple model of the firm's technology choice. Our model is a more general version of that presented by Bauman et al. (2008), and further modifies their model in two important respects. Firstly, we include a price of emissions, and secondly, we make the firm's technology choice explicit. 
Table 1: Summary of notation

\begin{tabular}{|c|c|}
\hline Notation & Description \\
\hline$i$ & $\begin{array}{l}\text { Subscript } i \text { denotes a technology. Technology } i \text { is fully charac- } \\
\text { terised by the four parameters }\left(\alpha_{i}, \beta_{i}, \gamma_{i}, c_{i}\right) \text {. The technology also } \\
\text { determines the firm's optimal level of input } x_{i} \text { and emissions } e_{i} \text {, } \\
\text { as seen in equation } 1 \text {. Subscript } 0 \text { is used to denote the firm's } \\
\text { starting technology. }\end{array}$ \\
\hline$\alpha_{i}$ & $\begin{array}{l}\text { The end-of-pipe effectiveness parameter. A higher } \alpha \text { indicates } \\
\text { that the technology is associated with a lower total cost of a given } \\
\text { level of end-of-pipe abatement. }\end{array}$ \\
\hline$\beta_{i}$ & $\begin{array}{l}\text { The emissions efficiency parameter. A higher } \beta \text { indicates that } \\
\text { the technology produces more units of gross emissions per unit of } \\
\text { input. }\end{array}$ \\
\hline$\gamma_{i}$ & $\begin{array}{l}\text { The productivity parameter. A higher } \gamma \text { indicates that a technol- } \\
\text { ogy produces more output per unit of input. }\end{array}$ \\
\hline$c_{i}$ & The technology-specific fixed cost of adoption. \\
\hline$x$ & $\begin{array}{l}\text { The firm's input. We use } x_{i} \text { to denote the firm's optimal input } \\
\text { choice for technology } i \text {. }\end{array}$ \\
\hline$z$ & The price per unit of input. \\
\hline$q$ & The price per unit of output. \\
\hline$p$ & The price per unit of emissions. \\
\hline$e$ & $\begin{array}{l}\text { The firm's level of emissions. We use } e_{i} \text { to denote the firm's opti- } \\
\text { mal level of emissions for technology } i \text {. }\end{array}$ \\
\hline $\bar{e}$ & $\begin{array}{l}\text { The initial allocation of emissions rights to the firm. This is zero } \\
\text { under an emissions tax, but may be positive under an emissions } \\
\text { trading scheme. }\end{array}$ \\
\hline$e_{i, \max }$ & $\begin{array}{l}\text { The technology-specific level of emissions when the price of emis- } \\
\text { sions is zero, } p=0 \text {. }\end{array}$ \\
\hline$Q=Q(x, \gamma)$ & $\begin{array}{l}Q \text { is the firm's total output, and } Q(\cdot) \text { is the firm's production } \\
\text { function, with } Q_{x}>0, Q_{x x}<0, Q_{\gamma}>0 \text {, and } Q_{x \gamma}>0 \text {. }\end{array}$ \\
\hline$G=G(x, \beta)$ & $\begin{array}{l}G \text { is the firm's gross emissions (i.e. prior to end-of-pipe abate- } \\
\text { ment), and } G(\cdot) \text { is the gross emissions function, with } G_{x}>0 \text { and } \\
G_{\beta}<0 \text {. }\end{array}$ \\
\hline$F=F(G-e, \alpha)$ & $\begin{array}{l}F \text { is the firm's total cost of end-of-pipe abatement, and } F(\cdot) \text { is } \\
\text { the total end-of-pipe abatement cost function, with } F_{G-e}>0 \text { and } \\
F_{\alpha}<0 \text {, whenever } G>e . F(0, \alpha)=0 \text {. Note that the firm's end- } \\
\text { of-pipe abatement is equal to gross emissions less final emissions } \\
(G-e) \text {. }\end{array}$ \\
\hline$f_{i}(e)$ & $\begin{array}{l}\text { The marginal abatement cost for technology } i \text { is a function of the } \\
\text { level of emissions, } e \text {. }\end{array}$ \\
\hline$\phi_{i}$ & $\begin{array}{l}\text { The change in the firm's maximum profit resulting from a switch } \\
\text { from technology } 0 \text { to technology } i \text {. }\end{array}$ \\
\hline$\Phi_{i}$ & That part of $\phi_{i}$ due to a market-based instrument. \\
\hline $\bar{r}$ & A reservation return on investment. \\
\hline
\end{tabular}


The firm's production function $Q=Q(x, \gamma)$ exhibits diminishing marginal returns to the input $x$. Both the level of output and the marginal product of $x$ are increasing in the productivity parameter $\gamma$. The input $x$ can be purchased at a per unit price of $z$, and the output can be sold at a per unit price $q$.

The firm faces a price on emissions, $p$. This price can be either a tax per unit of emissions or an equilibrium permit price in a competitive permit market. At price $p$ the firm must pay $p(e-\bar{e})$ to obtain the necessary emission rights, where $e$ is final emissions and $\bar{e}$ is the initial allocation of rights. It is costly to reduce emissions. More specifically, the firm's total end-of-pipe abatement cost is given by $F=F(G-e, \alpha)$, which is increasing in end-of-pipe abatement $(G-e)$, and decreasing in the effectiveness of the end-of-pipe technology $\alpha$, whenever $G>e . F(0, \alpha)=0 . G$ is gross emissions, which is increasing in input use and decreasing in the emissions efficiency parameter $\beta$. End-of-pipe abatement is the difference between $G$ and final emissions $e$.

The parameters $\alpha_{i}, \beta_{i}$, and $\gamma_{i}$ then describe technology $i$. In addition, the (certainty equivalent) fixed cost of adopting/developing technology $i$ is $c_{i}$.

With a price of emissions $p$, a firm using technology $i$ can earn a maximum profit of

$$
\pi_{i}=\max _{x, e}\left[q Q\left(x, \gamma_{i}\right)-z x-p(e-\bar{e})-F\left(G\left(x, \beta_{i}\right)-e, \alpha_{i}\right)\right]
$$

Let $x_{i}$ denote the profit maximising input choice, and $e_{i}$ the profit maximising level of emissions. The incentive to invest in a new technology $i$ can then be written as the difference between profits earned with the new technology and the profits earned with the initial technology (for convenience, let us denote the initial technology by subscript $0)$. Formally, we write

$$
\begin{aligned}
\phi_{i}= & \pi_{i}-\pi_{0} \\
= & q\left[Q\left(x_{i}, \gamma_{i}\right)-Q\left(x_{0}, \gamma_{0}\right)\right]-z\left(x_{i}-x_{0}\right) \\
& -\left[F\left(G\left(x_{i}, \beta_{i}\right)-e_{i}, \alpha_{i}\right)-F\left(G\left(x_{0}, \beta_{0}\right)-e_{0}, \alpha_{0}\right)\right]+p\left(e_{0}-e_{i}\right)
\end{aligned}
$$

The first two terms on the righ-hand-side give us the changes in profit resulting from changes in revenue and input costs. The last two terms give us the changes in profit resulting from changes in abatement costs and payments for emission rights.

These last two terms represent the incentive for investment into technology $i$ provided by the market-based instrument. They both drop out when the price of emissions is zero. ${ }^{1}$ Let $x_{i, \max }$ and $e_{i, \max }$ respectively denote the optimal input choice and emissions with technology $i$ when the price of emissions is zero.

\footnotetext{
${ }^{1}$ The first term drops out since the firm would never optimally incur any end-of-pipe abatement (i.e. it would set $G=e$ with any technology, so $F=0$ ), and the second term drops out trivially.
} 
Since we are especially interested in that part of the incentive for innovation provided by the market-based instrument, let us define this concept separately as

$$
\Phi_{i}=F\left(G\left(x_{0}, \beta_{0}\right)-e_{0}, \alpha_{0}\right)-F\left(G\left(x_{i}, \beta_{i}\right)-e_{i}, \alpha_{i}\right)+p\left(e_{0}-e_{i}\right)
$$

Notice that, when the firm faces a given price $p$, as would be the case under an emissions tax or in a competitive permit market, the initial allocation of emission rights $\bar{e}$ does not affect a profit maximising firm's incentive to invest in new technologies (Requate, 2005). ${ }^{2}$

$\Phi_{i}$ can also be represented graphically. The function $F\left(G\left(x_{i}, \beta_{i}\right)-e_{i}, \alpha_{i}\right)$ gives the total cost of emissions abatement at the optimal emissions level with technology $i$. We write the corresponding marginal abatement cost as $f\left(G\left(x_{i}, \beta_{i}\right)-e_{i}, \alpha_{i}\right)$. Now imagine allowing ourselves to deviate from the optimal level of emissions for a given technology $i$. $f(\cdot)$ then gives us the marginal abatement cost curve. Since $i$ still fixes $G$ and $\alpha_{i}$, we can simplify our notation and let $f_{i}(e)$ denote the marginal abatement cost curve for technology $i . f_{i}(e)$ is a decreasing function of emissions $e$. This curve illustrated in figure 1 , where we have put final emissions $e$ on the horizontal axis.

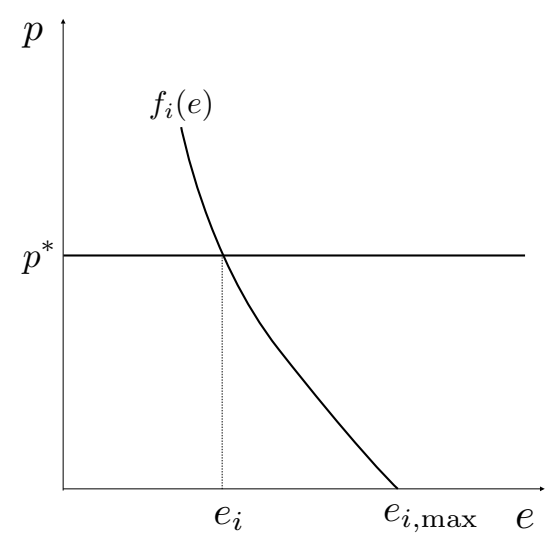

Figure 1: With technology $i$, the firm's 'demand for emissions' is $f_{i}(e)$. At a given emissions price, $p^{*}$, the firm would optimally emit $f_{i}^{-1}\left(p^{*}\right)=e_{i}$. The firm would optimally emit $e_{i, \max }$ if the emissions price were zero.

To harmonise the algebraic and graphical representations, we can rewrite equation 3 using the notation for marginal abatement costs.

$$
\Phi_{i}=\int_{e_{0}}^{e_{0, \max }} f_{0}(e) d e-\int_{e_{i}}^{e_{i, \max }} f_{i}(e) d e+p\left(e_{0}-e_{i}\right)
$$

\footnotetext{
${ }^{2}$ The same conclusion can also be deduced from Hahn (1984), who shows that the level of emissions a price-taking firm is independent of its initial allocation of emissions rights.
} 
The net gain from adopting technology $i$ is obtained by subtracting the cost of adoption, $c_{i}$, from the total gain, $\phi_{i}$. Formally, a profit maximising firm will only invest in technology $i$ if

$$
\phi_{i}-c_{i} \geq \max \left(\phi_{1}-c_{1}, \ldots, \phi_{i-1}-c_{i-1}, \phi_{i+1}-c_{i+1}, \ldots, \phi_{I}-c_{I}, \bar{r}\right)
$$

where $\bar{r}$ is a reservation return. Equation 5 is an investment condition, and defines the firm's technology choice problem.

We have introduced a lot of notation in this section. Table 1 summarises all of the notation for easy reference.

One salient feature of our set-up is the four-parameter family of technologies, $(\alpha, \beta, \gamma, c)$. We can choose these parameters to describe any physical technology of interest, and any level of investment in this physical technology. Therefore, this analytical framework can simultaneously address questions about what physical technology to invest in, and how much to invest in it.

Another feature of our model is the simplicity of the firm's expectations about the gains from innovation and investment in new technologies. The firm considers only it's own choice, holding everything else constant. In section 3 we consider what happens when the circumstances warrant more complicated expectations. But first let us see what we can already glean about how the price of emissions affects the firm's technology choices.

\subsection{Incentives to invest in abatement technologies}

Now that we have set out our basic model both algebraically and graphically, the first task is to examine the firm's incentives for investing in different types of technologies. ${ }^{3}$

\section{End-of-pipe innovations (increases in $\alpha$ )}

Let us begin by considering the emitter's incentive to develop and adopt an end-of-pipe technology $(E O P)$. The original argument that market-based instruments encourage innovation considered just such a technology (see, for instance, Tietenberg, 1985, Downing and White, 1986, Malueg, 1989, and Milliman and Prince, 1989), and it remains the most commonly discussed technology in the literature (see, for instance, Fischer et al., 2003 and Weber and Neuhoff, 2010). End-of-pipe technologies filter the exhaust of a production process, but do not actually affect production itself. This means that

\footnotetext{
${ }^{3}$ This section borrows from and significantly extends the discussion of different technologies in Bauman et al. (2008).
} 
$x_{0}=x_{E O P}$, so that in this case $\phi_{i}=\Phi_{i}$. In other words, end-of-pipe abatement has no impact on sales revenues and input costs. The end-of-pipe innovation does, however, increase $\alpha$ from $\alpha_{0}$ to $\alpha_{E O P}$. As a consequence, the firm faces a lower marginal benefit of emissions for every positive level of emissions $\left(f_{E O P}(e)<f_{0}(e)\right.$ for all $\left.e>0\right)$.

Graphically, the result is a downward pivot of the the inverse demand curve around the point $e_{\max }$ (see figure 2). $\Phi_{i}$ is given by the area $A$ in figure 2. As figure 2 also illustrates, the optimal amount of emissions will always be lower with the end-of-pipe technology installed. The incentive to adopt a given end-of-pipe technology is therefore increasing in the allowance price.

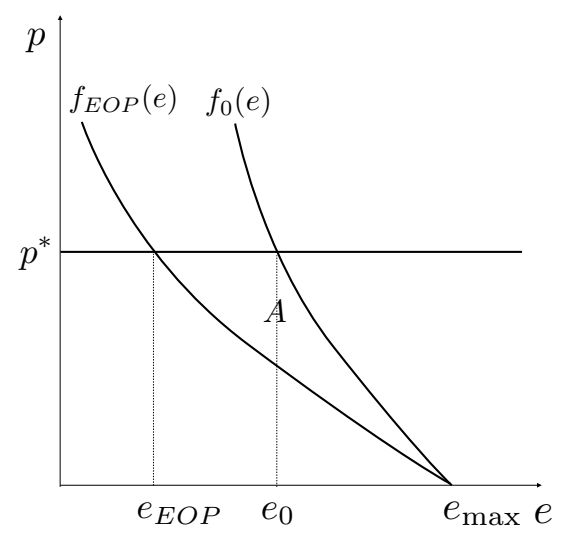

Figure 2: End-of-pipe innovations: The inverse demand curve pivots downward as a result of adopting an end-of-pipe technology.

Traditionally, end-of-pipe innovations have been modeled as a 'discrete' technology. Whatever the firm's starting technology, adopting the end-of-pipe innovation results in the same marginal abatement cost curve. This means that a firm with an initially steeper marginal abatement cost curve would stand to gain more from the end-of-pipe innovation. Weber and Neuhoff (2010), however, consider 'proportional' end-of-pipe innovations, so that investing in innovation pivots the marginal abatement cost curve downward from its original position in proportion to the level of investment. ${ }^{4}$ A given investment in a 'proportional' end-of-pipe innovation is then more attractive to a firm with initially shallower marginal abatement cost curve, ${ }^{5}$ the exact opposite of the 'discrete' technology. Figure 3 illustrates this point.

Irrespective of whether end-of-pipe innovations are 'discrete' or 'proportional', the

\footnotetext{
${ }^{4}$ Although innovation and emissions have stochastic components in their model, their comparative statics are conducted in terms of expected returns on investment, and so is fully comparable with the present analysis.

${ }^{5}$ This point is made clear in equation (5) in Weber and Neuhoff (2010).
} 


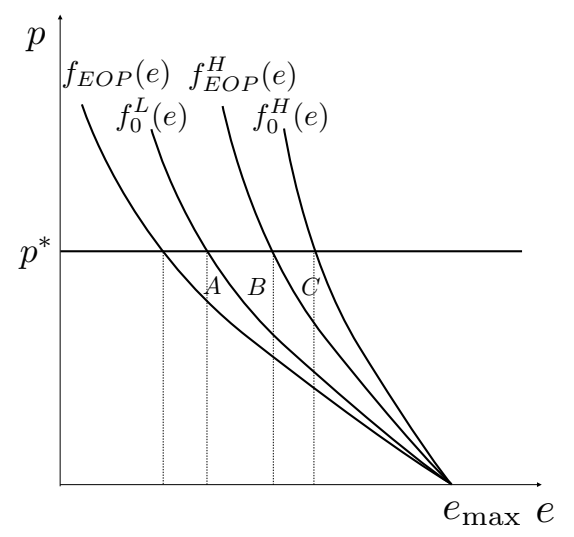

Figure 3: 'Discrete' and 'proportional' end-of-pipe innovations: With a 'discrete' end-ofpipe innovation, the firm's marginal abatement cost curve becomes $f_{E O P}(e)$ if it adopts the new technology, whether they start out with a shallow curve $f_{0}^{L}(e)$ or a steep curve $f_{0}^{H}(e)$. The incentive to adopt the 'discrete' end-of-pipe technology is given by the area $A$ in the former case, and $A+B+C$ in the latter. With 'proportional' end-of-pipe innovations, however, firm's do not end up with the same marginal abatement cost curve after equivalent investments. Rather, this results in equivalent pivots of their marginal abatement cost curves - from $f_{0}^{L}(e)$ to $f_{E O P}(e)$ and from $f_{0}^{H}(e)$ to $f_{E O P}^{H}(e)$. In this case, the incentive to innovate is $A$ when starting with a shallow curve, and $C$ when starting with a steeper curve, where $A>C$.

incentive to adopt a given end-of-pipe technology $\Phi_{i}$ is increasing in the price of emissions $p$. This is one of the classic arguments for pollution pricing (Tietenberg, 1985; Downing and White, 1986). However, it must be noted that it was originally used in reference to sulphur-scrubbers in the U.S. Acid Rain Program. If we look instead at carbon markets such as the EU Emissions Trading Scheme, however, very few end-of-pipe technologies for carbon producing processes are near market, with the possible exception of Carbon Capture and Storage. Therefore, this particular argument does not provide a very convincing case for carbon prices. It would therefore be valuable to consider the incentives market-based instruments provide for investment in other types of abatement technologies.

\section{Efficiency-enhancing innovations (increases in $\beta$ )}

Consider the incentive to adopt an efficiency-enhancing technology, $E$, which increases $\beta$ from $\beta_{0}$ to $\beta_{E}$. The output produced with one unit of input is unchanged, but the emissions per unit of input is reduced. Consequently, a more drastic reduction of output would now be needed to abate one unit of emissions. In other words, the marginal abatement cost rises more steeply $\left(f_{E}^{\prime}(e)<f_{0}^{\prime}(e)\right.$ for all $\left.e\right)$. Moreover, as long as the 
end-of-pipe technology is the same, the emitter's profits whenever he is emitting nothing remains the same, regardless of whether he adopts the efficiency-enhancing innovation or not $\left(F_{0}(0)=F_{E}(0)\right)$. Seen graphically, the marginal abatement cost curve is steeper, but the area beneath the curve is the same. The incentive to invest provided by the market-based instrument, $\Phi_{i}$, is given by the area $A-B$ in figure 4 .

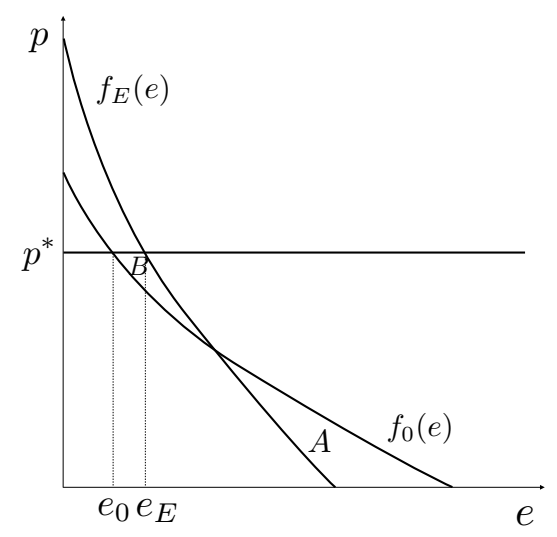

Figure 4: Efficiency-enhancing innovations: The marginal abatement cost curve becomes steeper when adopting efficiency-enhancing technologies, but the area beneath the curve remains constant.

The first thing to note is that the optimal amount of emissions may either increase or decrease as a result of an efficiency-enhancing innovation. Somewhat counterintuitively, efficiency-enhancing innovations are likely to increase emissions at a higher emissions price $p$, and the incentive for adoption of the technology is therefore weaker for a higher emissions price. The reasoning goes as follows. While it had previously been optimal to draw down production at a high price of emissions, the new technology increases the benefit of emitting an extra unit. The higher the price, the less you were already emitting, and the more you now gain from increasing emissions. When the price of emissions is high, increasing emissions would be more expensive, so the firm would have a weaker incentive to adopt the efficiency-enhancing technology in the first place.

The converse line of reasoning suggests that efficiency-enhancing innovations are likely to reduce emissions at a low emissions price, and that the incentive to adopt the technology is stronger at a lower price. The incentive for technology adoption reaches a maximum when $p=f_{E}(e)=f_{0}(e)$ in figure 4 , and thereafter declines as the emissions price falls further. Thus, contrary to the standard arguments that refer to end-ofpipe technologies, a lower price of emissions (to a point) may actually give stronger incentives for investment for efficiency-enhancing technologies. For sectors where the 
bulk of innovations are expected to be of the efficiency-enhancing type, this may be a lesson worth bearing in mind.

\section{Process innovations (increases in $\gamma$ )}

Next, consider the incentive to adopt a process innovation, $P$, causing an increase in $\gamma$ from $\gamma_{0}$ to $\gamma_{P}$. Process innovations increase the amount of output per unit of input, but does not affect emissions per unit of input. A process innovations might affect the optimal scale of production and emissions, and a price on emissions may therefore provide an incentive or disincentive to adopt such technologies.

Even when the price of emissions is zero, a process innovation may increase the optimal scale of production, and hence emissions $\left(e_{P, \max }>e_{0, \max }\right)$ or reduce it $\left(e_{P, \max }<\right.$ $\left.e_{0, \max }\right) .{ }^{6}$ A process innovation, moreover, may in principle be associated with either decrease or increase in the cost of abating all the way to zero emissions $\left(F_{0}(0)-F_{P}(0) \lessgtr\right.$ $0)$. There are then four interesting cases of process innovations (see figure 5):

$\mathbf{P 1}\left\{e_{P 1, \max }<e_{0, \max }, F_{0}(0)-F_{P 1}(0)<\epsilon\right\}$ : With a reduction in optimal level of unconstrained emissions and an increase or small reduction in the cost of full abatement (here represented as being less than some positive quantity $\epsilon$ ), the horizontal intercept of the marginal abatement cost curve decreases (i.e. $e_{P 1, \max }>$ $\left.e_{0, \max }\right)$, but the vertical intercept increases (i.e. $\left.f_{P 1}(0)>f_{0}(0)\right)$. As panel $P 1$ of figure 5 illustrates, this looks similar to adoption of an efficiency-enhancing innovation. The incentive to invest is given by the area $A-B$, and is increasing in the price of emissions up to the point where $p=f_{0}(e)=f_{P 1}(e)$ in the first panel of figure 5 , and thereafter decreasing in the price of emissions.

$\mathbf{P 2}\left\{e_{P 2, \max }<e_{0, \max }, F_{0}(0)-F_{P 2}(0)>\epsilon\right\}$ : With a reduction in optimal level of unconstrained emissions and a large reduction in the cost of full abatement, the marginal abatement cost curve shifts inward so that the whole curve lies beneath the old curve (i.e. $f_{P 2}(e)<f_{0}(e)$ for all $e$ ), as illustrated in panel $P 2$ in figure 5. The incentive to invest is given by area $A$, and is increasing in the price of emissions.

P3 $\left\{e_{P 3, \max }>e_{0, \max }, F_{0}(0)-F_{P 3}(0)<\epsilon\right\}$ : With an increase in optimal level of unconstrained emissions and an increase or small reduction in the cost of full

\footnotetext{
${ }^{6}$ One economic rationale for this is market power. If demand for the firm's output is very elastic, the firm would increase production when the marginal costs of production falls. If demand is inelastic, the firm may optimally restrict its production.
} 

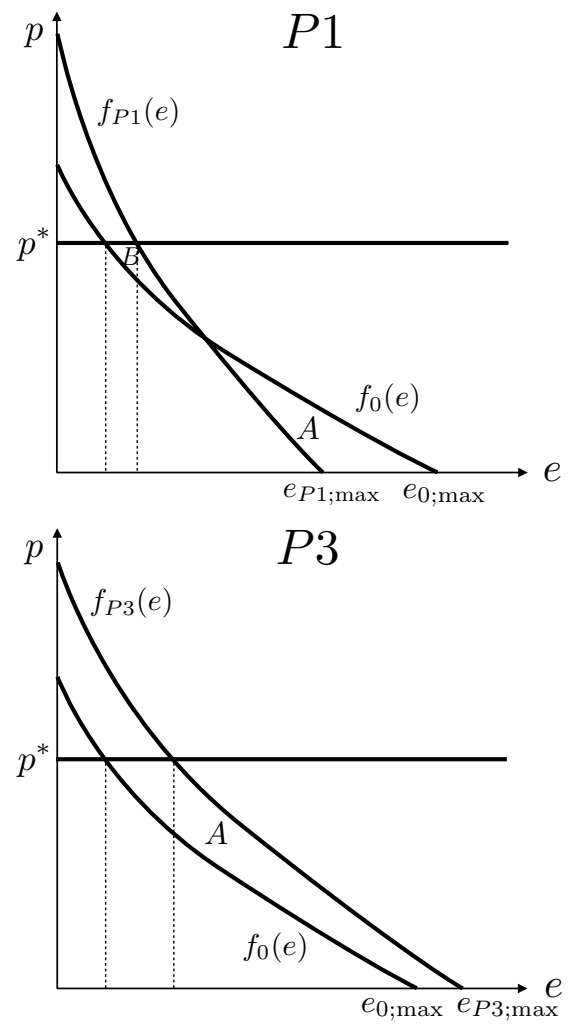
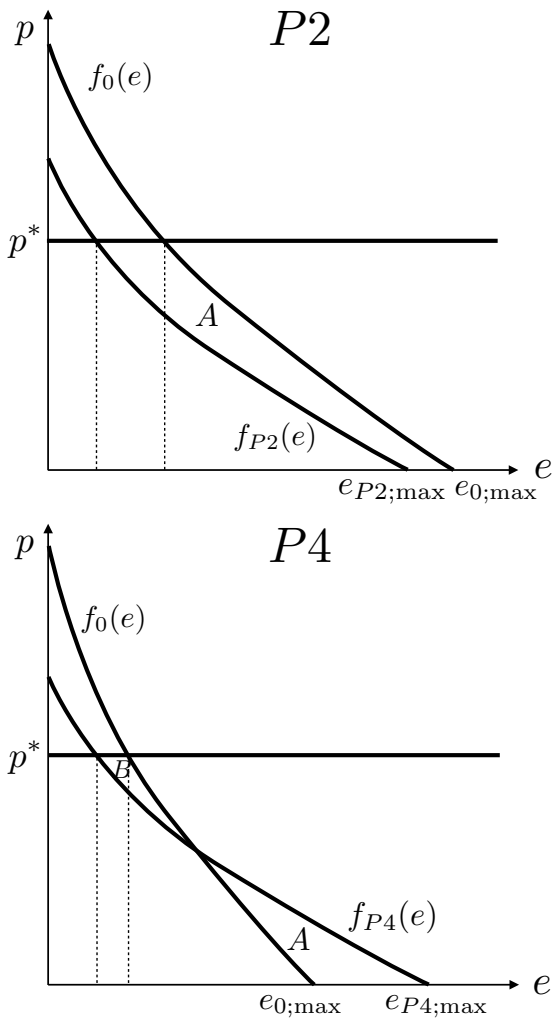

Figure 5: Process innovations: Depending on the optimal scale of production at a zero emissions price and the change in the cost of full abatement, process innovations can cause a variety of shifts of the marginal abatement cost curve.

abatement, the marginal abatement cost curve shifts outward so that the whole curve lies above the old curve (i.e. $f_{P 3}(e)>f(e)$ for all $e$ ), as seen in panel $P 3$ of figure 5. The disincentive to invest is given by $A$, and is increasing in the price of emissions.

$\mathbf{P} 4\left\{e_{P 4, \max }>e_{0, \max }, F_{0}(0)-F_{P 4}(0)>\epsilon\right\}:$ With an increase in the optimal level of unconstrained emissions and a large reduction in the cost of full abatement, the horizontal intercept of the marginal abatement cost curve increases, but the vertical intercept decreases, as illustrated in panel $P 4$ of figure 5 . The incentive to invest provided by the emissions price, $\Phi_{P 4}$, is given by $B-A$. This type of process innovation increases the optimal level of emissions at a low price, but reduces emissions at a high price. A low price therefore discourages this type of innovation, and the disincentive initially becomes stronger as the price price of emissions increases. The incentive reaches a minimum when $p=f_{P 4}(e)=f(e)$, 
and thereafter increases with the allowance price.

Note that the impact of a market-based instrument on the firm's incentive to adopt process innovations depends on how the innovation would affect the firm's optimal scale of production. Hence, the market conditions in the output markets in which the emitters operate may influence the firm's incentives to invest in different process innovations. A single economy-wide price on emissions, therefore, will therefore almost inevitably shift investments between economic sectors and between different technologies.

\section{Replacement innovations (very large increases in $\alpha$ or $\gamma$ )}

Until now we have looked at innovation and investment in abatement technologies. However, another type can be described as replacement technologies, $R$ (Laffont and Tirole, 1996a,b; Scotchmer, 2010). Replacement technologies eliminate the need for abatement as such. A fully efficient end-of-pipe technology or a pollution-free perfect substitute for the polluting good would fall into this category. In our model, these would respectively be represented as a very large increase in $\alpha$ or $\gamma$. With such technologies, the optimal amount of emissions is always zero, so $e_{R, \max }=0$. Graphically, the incentive to invest in replacement technologies is the whole area beneath the marginal abatement cost curve which falls below the price of emissions, $p$. The incentive to innovate and invest in replacement technologies is always increasing in the allowance price.

\subsection{Market-based instruments and technology choices}

We can now compare the incentives to invest in different technologies. For convenience, figure 6 summarises how the gains provided by the market-based instrument, $\Phi_{i}$, depends on the price of emissions.

One of the more surprising features of figure 6 is that the incentive for investment in abatement technologies is not always an increasing function of the emissions price. For some technologies, a lower price price of emissions (to a point) may actually provide a greater incentives for innovation. This finding derives from very conventional and almost model-free assumptions, yet sharply contrasts with the conventional wisdom. To the author's knowledge, these implications of the standard theory have not previously been articulated.

Firgure 6 also emphasizes the importance of opportunity cost in technology choice. A higher emissions price not only affects overall incentive for innovation and investment in clean technologies, but also the relative attractiveness of alternative technologies. 


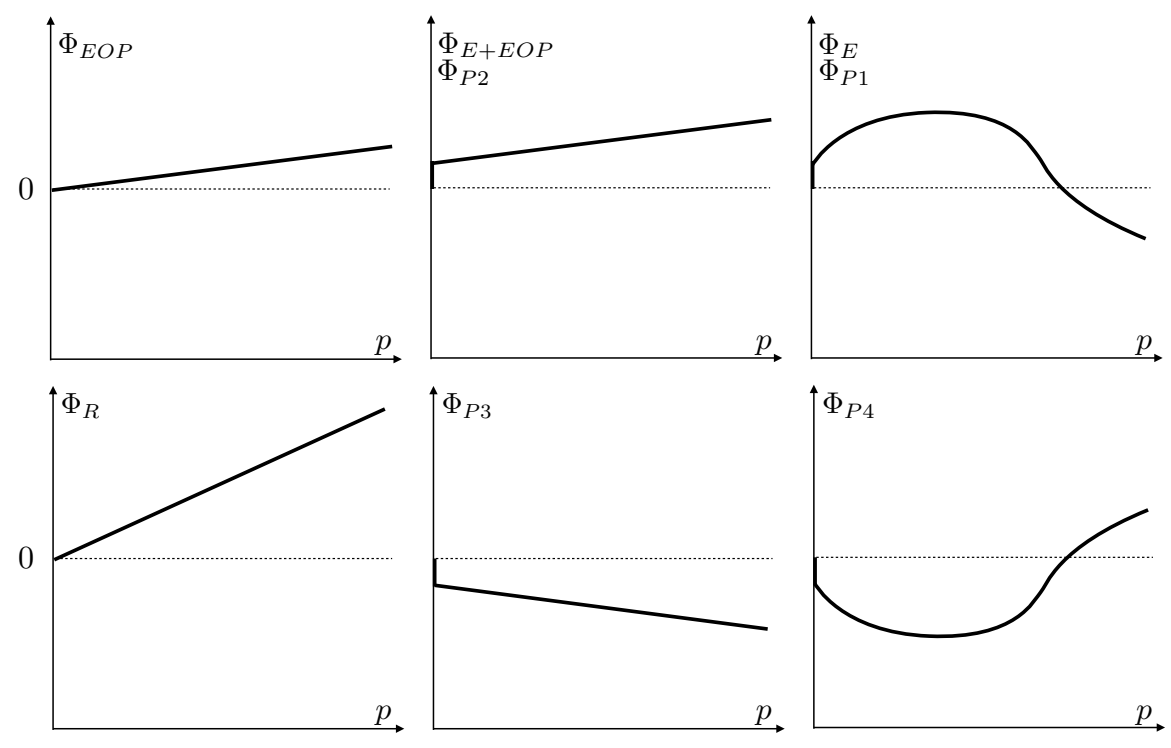

Figure 6: Incentives for investment: The six stylized panels illustrate how the incentives for adopting technologies of different types depend on the the price of emissions, $p$. To facilitate comparisons, the certainty equivalent cost of adopting each technology, $c_{i}$, is assumed to be zero for all technologies. A positive $c_{i}$ would simply shift the curves vertically down.

For instance, in figure 6, the efficiency-enhancing innovation $(E)$ looks relatively more attractive at lower emissions prices, while the replacement technology $(R)$ becomes much more attractive at higher prices. Incorporating many different types of innovations into a coherent analytical framework emphasizes that the firm's problem is not just how much to invest, but one of technology choice.

\section{Extensions of the model}

Even the simple model in section 2 yields many insights into the effect that market-based instruments have on the firm's technology choices. Yet, the analysis made a central simplifying assumption - an exogenously given emissions price. Although it would be rational for the firm to act as a price-taker with respect to the emissions price in this setting, there is no general justification for assuming that the price of emissions does not also respond to technology choices. This section looks at how optimal technology choices change when the price of emissions is endogenous. One of the things we will see 
is that emissions taxes and permits are no longer equivalent.

\subsection{Innovation and investment in equilibrium}

In some settings, firms' technology choices may affect the emissions price they face. For instance, the price set in a permit market responds to changes in demand for permits, which this in turn depends on technology choices. In order to characterise the relationship between the equilibrium permit price, $p^{*}$, and the number of firms that adopt new technologies, $n$, we need to know whether adopting the technology increases or decreases the firm's optimal level of emissions. Based on our previous analysis, we know that adopting one of the technologies $E O P, P 2$, or $R$, unambiguously reduces the optimal amount of emissions. Adopting $E$ or $P 1$ reduces emissions if the emissions price is sufficiently low, and $P 4$ reduces emissions if the price is sufficiently high. We shall refer to these situations collectively as emissions-reducing innovations. For P3, emissions unambiguously increase. Emissions also increase when the price of emissions is sufficiently high with $E$ and $P 1$, as well as for $P 4$ when the price is sufficiently low. We shall refer to these situations as emissions-increasing innovations. Note that for some technologies, the price of emissions determines whether the innovation is emissions-reducing or emissions-increasing.

Requate and Unold (2003) consider adoption of emissions-reducing innovations. With such technologies, adoption reduces demand for permits, so the equilibrium price falls $\left(p^{*^{\prime}}(n)<0\right)$ and the gains from innovation and investment therefore also decrease $\left(\Phi_{i}^{\prime}(n)<0\right.$, since $\Phi_{i}$ is an increasing function of the emissions price for emissionsreducing innovations). Non-innovating firms share in the reduced abatement costs that come from a lower emissions price despite not investing themselves. They are free-riding on the innovators (Requate and Unold, 2003). This is illustrated in figure 7. If only one firm were to adopt an emissions-reducing innovation, it would stand to gain profits equal to the area $A+B$. More widespread technology adoption, however, reduces aggregate demand for permits. Since the supply of permits is fixed, their price falls. If the firm expects the price to fall to $p^{\prime}$ as the technology spreads, the expected gain from adopting the technology would equal only area $A$.

The converse reasoning applies to emissions-increasing innovations. The permit price increases as the innovation spreads $\left(p^{* \prime}(n)>0\right)$, since firms demand more permits. Since the incentive for investment is decreasing in the emissions price for emissions-increasing innovations, prior adoption again reduces the gains for further adoption $\left(\Phi_{i}^{\prime}(n)<0\right)$. Thus, when the price price of emissions is set in a permit market, more widespread 


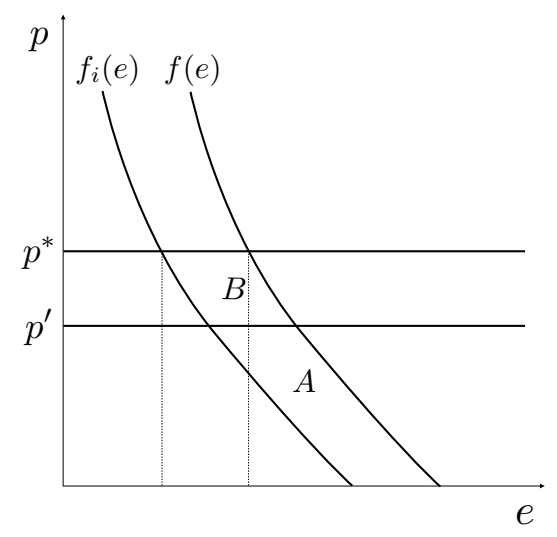

Figure 7: Incentives in equilibrium: The incentive to adopt an emissions-reducing innovation $i$ is given by area $A+B$ when the equilibrium price is $p *$. The incentive for adoption is smaller, area $A$, when the price has fallen from $p^{*}$ to $p^{\prime}$. The change in the price can be brought about if a sufficient number of emitters adopt the emissions-reducing innovation. This figure is adapted from Requate and Unold (2003).

technology adoption always reduces the gains from adopting any type of innovation.

Three important clarifications are in order here. Firstly, a forward-looking firm would only consider the gain in equilibrium, i.e. $\Phi_{i}\left(p^{\prime}\right)$ calculated at the emissions price that obtains when the equilibrium number of firms have adopted the technology, $p^{\prime}$. This is given by area $A$ in figure 7. The incentive to invest in technology $i$ is then independent of the number of firms that have adopted the technology so far. However, for a firm that acts on the basis of the currently prevailing equilibrium emissions price $p^{*}$, whether because they are myopic or because they do not have good enough information about future equilibrium prices, the incentive to adopt a new technology depends on the number of prior adopters at any given point. In this situation, the incentive for investment is different for early adopters $(A+B$ in figure 7$)$ and late adopters $(A)$.

Secondly, for a given cost of adoption $c_{i}$, we may have partial technology diffusion in equilibrium. The price of emissions responds to technology adoption, and firms would stop adopting only when $A=c_{i}$. Partial adoption would not be possible with an emissions tax, since the emissions price faced by firms is constant and independent of technology adoption.

Thirdly, it is important to note that prior adoption reduces the gains from further adoption only for the same type of innovation (i.e. emissions-reducing or emissionsincreasing). Adopting emissions-reducing innovations puts downward pressure on the permit price, and hence on the incentive for further adoption of emissions-reducing innovations. However, a lower allowance price increases the incentive to adopt emissions- 
increasing innovations. Conversely, adopting emissions-increasing innovations puts upward pressure on the allowance price, and hence increases the incentive to adopt emissionsreducing innovations. On route to a stable emissions price, adoption of an emissionsreducing innovation by one firm may induce another to adopt an emissions-increasing innovation, and so on. An equilibrium involves a stable portfolio of technologies across firms. However, our model does not yield much information about what the final portfolio of technologies will look like. ${ }^{7}$ We return to this issue in section 3.4.

\subsection{Market power}

Let us continue with an emissions price set in a permit market. In a competitive market, as above, diffusion of an emissions-reducing innovation reduces the permit price, but the technology choice of each firm has no noticeable impact. This is a world of small emitters. However, as Oates and Strassman (1984) note, a large proportion of emissions are often, unsurprisingly, accounted for by large emitters. When the innovating firm is a large enough emitter, selling permits would cause a noticeable drop in the price. Conversely, buying permits would cause a noticeable increase in the price. The price of emissions $p$ is then an increasing function of the level of emissions $e$, and a decreasing function of the initial allocation of emissions rights $\bar{e}\left(p_{e}>0\right.$ and $\left.p_{\bar{e}}<0\right) .{ }^{8}$ For a large enough emitter, therefore, the price of emissions would be plotted as an upward sloping curve in 'price-emissions'-space. The curve shifts downward for more generous initial allocations of emissions rights, $\bar{e}$. Figure 3.2 illustrates.

Suppose the emitter is initially allocated the right to emit up to the point $\tilde{e}$ and the initial equilibrium price is $p^{*}$. Taking account of how its own purchasing decisions affects the emissions price, the firm would purchase $\hat{e}-\tilde{e}$ permits if it did not adopt technology $i$. Because the firm would avoid pushing up the price for each additional permit it wants to purchase, the gain from adopting technology $i$ is given by area $A+B+C$. By contrast, if the initial allocation is such that the firm is allowed to emit up to $\hat{e}$ and the equilibrium price is $p^{*}$, the firm would optimally sell $\hat{e}-\tilde{e}$ permits if it adopted technology $i$. Taking into account the fact that the firm fetches a lower price for each additional permit it tries to sell, the gain from technology adoption is now only equal to area $A$. Had the firm been a price-taker with respect to the emissions price, the gain from adopting technology $i$ would have been equal to area $A+B$ regardless of the initial allocation of emissions

\footnotetext{
${ }^{7}$ See Moreno-Bromberg and Taschini, 2011 for dynamic simulations of this problem, which do provide more information about what technologies firms adopt in equilibrium.

${ }^{8}$ See Kennedy and Laplante (1999) for a more general argument that the emissions price $p$ is an increasing function of $e$.
} 


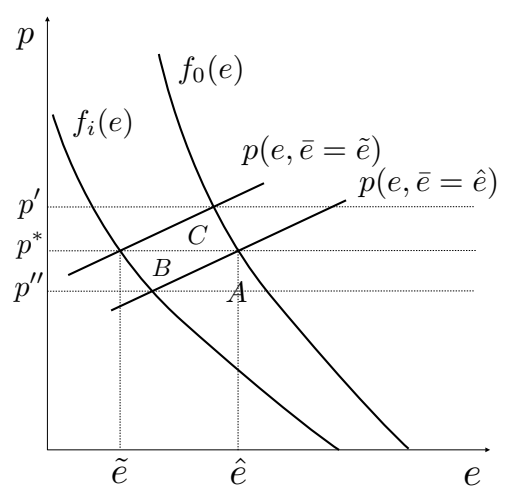

Figure 8: Market power and initial emissions allocation: A generous initial allocation of allowances, $\hat{e}$, means that the firm would be faced with selling excess allowances until the price falls to $p^{\prime \prime}$, should it adopt technology $i$. The gain is given by area $A$. A stringent initial allocation, $\tilde{e}$, on the other hand, means the firm has would have to purchase allowance up to the price $p^{\prime}$ if it did not adopt technology $i$. The gain from investment is therefore given by area $A+B+C$. The converse argument yields losses $A+B+C$ and $A$, respectively, for an emissions-increasing innovation.

rights.

It is straightforward to modify our simple model from section 2 . We simply need to make the price of emissions an increasing function of $e$ and a decreasing function of $\bar{e}$, rather than a constant. Instead of equation 4, the gain from adopting technology $i$ is now

$$
\Phi_{i}=\int_{e_{0}}^{e_{0, \max }} f_{0}(e) d e-\int_{e_{i}}^{e_{i, \max }} f_{i}(e) d e+\int_{e_{i}}^{e_{0}} p(e, \bar{e}) d e
$$

As equation 6 shows, the incentive to innovate now depends on the initial allocation of emissions rights. For large emitters, a more stringent initial permit allocation appear to provide greater incentives for investment in clean technologies.

This discussion also highlights that when tradable emissions permits are used, the relationship between the price on emissions and the incentives for investment also depends on the strategic interactions between emitters. This issue would never arise for an emissions tax, where the price on emissions is just a constant.

\subsection{Imperfect competition}

Let us now combine the two extensions from above: incentives in equilibrium and market power. Now each firm has market power in either the output or permit market, or both, 
and it considers the change in equilibrium in both markets resulting from its technology choices.

In the case with an imperfectly competitive permit market, $p^{\prime}(e)>0$, but perfectly competitive output market, the earlier conclusions are still valid. The incentive to invest in emissions-reducing innovations is decreasing in the investments made by competitors in the permit market, as well as being muted by the firm's own market power (Storrøsten, 2010). Net permit buyers will have greater incentives to adopt innovations since they benefit from a lower permit price, while net sellers have diminished incentives. This implies that a firm is likely to underinvest when allowances are freely allocated, while full auctioning encourages over-investment in new technologies (Montero, 2002a).

Consider now the reverse: a situation with a perfectly competitive permit market (i.e. $p(e)=p^{*}$ for all $e$ ), but competition à la Cournot in the output market (so that, give the competitor's equilibrium response, the output price $q$ is a decreasing function of the firm's output $Q$ ). In this scenario, innovation that reduces the marginal cost of abatement puts downward pressure on the permit price for a given level of emissions, and the innovating firm actually increases output to exactly offset this effect (Montero, 2002a). The price of emissions is therefore unchanged, and the incentive to invest is the same as in the previous section.

When we combine imperfect competition in the allowance market with Cournot competition in the output market, the analysis becomes slightly more intricate. Imperfect competition in the allowance market still means that net permit buyers have greater incentives for innovation than do net sellers. However, innovation now has an additional effect. Although the reduced marginal cost of abatement encourages the innovator to increase output, this does not completely offset the downward pressure on the permit price. The lower price reduces the marginal abatement costs of competitors, who consequently increase their output. In essence, when there is imperfect competition in both the permit and output markets, innovation has a spillover effect through the permit market, which is then fed back to the innovating firm in the form of stiffer competition. The incentives for innovation and investment are dampened because of this spillovereffect (Montero, 2002a). In equilibrium, the permit and output prices are lower, and total output is higher. Montero (2002b) examines the case where emitters compete à la Bertrand with differentiated products. Although the reasoning is slightly different, the results for are qualitatively very similar for an emissions price set in a permit market. 


\subsection{Heterogeneous firms}

One of the problems mentioned in section 3.1 is that, although there might be an equilibrium corresponding to some set of technologies being adopted, our model does not tell us how that equilibrium would actually come about in practice. Identical firms would all have exactly the same incentive to adopt a given technology. Hence, if there are $N$ firms, $M$ of which will adopt technology $i$ in equilibrium, there are $\left(\begin{array}{l}N \\ M\end{array}\right)$ equilibria which differ only in which firms have adopted a given technology. In the simple model, all of these outcomes are equally plausible.

One suggested solution is to set the investment decision within an extensive form game, in which case there is a unique sub-game perfect Nash equilibrium, depending on the order of movers (Storrøsten, 2010). However, the problem is now instead how to order the players. There would be $N$ ! equally plausible extensive form games, which once again yield a total of $\left(\begin{array}{l}N \\ M\end{array}\right)$ equilibria. We have only shifted the problem one step.

The problem here is not whether the model is static or dynamic, but rather that firms are identical. Heterogeneity among firms not only gets rid of the problem, but also seems more plausible. Heterogeneity can be incorporated in a number of ways. Firms might for instance have different initial technologies, in which case they would face different marginal abatement cost curves. Weber and Neuhoff (2010) introduce firm heterogeneity in this way, without greatly increasing the complexity of the analysis.

Differences between firms could also be introduced through the cost of technology adoption, $c_{i}$. Firms may differ, for instance, in their abilities to raise internal and external funds (Cramton and Kerr, 2002).

The cost of technology adoption may also vary dynamically as a result of the processes at work as innovations are adopted. For instance, the originator of a technology usually incurs greater costs in adopting the technology than subsequent firms adopting the same technology. Differences in the cost of adoption may still be present between the $n^{\text {th }}$ and the $(n+1)^{\text {th }}$ firm to adopt a technology, due to 'learning-by-doing', network externalities, or other types of economies of scale. The cost of technology adoption will then be a decreasing function of the number of prior adopters. ${ }^{9}$ This might also mean that, although early adoption reduces the potential gain from later adoption, the $\operatorname{cost} c_{i}$ may fall more than enough to compensate. If this effect is sufficiently strong, economies of scale would come to dominate once a certain threshold has been reached, and we would observe the well known S-shaped pattern for the diffusion of technology.

The cost of innovation could of course instead be an increasing function of the number

\footnotetext{
${ }^{9}$ This possibility is cursorily considered by Requate (2005).
} 
of previous adopters. This might be the case if, say, a large cost component of the new technology is the cost of some finite resource (e.g. precious metals in catalysts and solar panels). The cost of the technology may then rise as the resource is depleted. In this case, the gains from later technology adoption may be doubly undermined by early adoption - both through the drop in the permit price (in permit markets) and through the rising cost of technology adoption.

Firm heterogeneity can be easily accommodated within our analytical framework. Moreover, our discussion highlights the opportunity here to kill two birds with one stone - resolving the modeling problem of having too many equilibria, and making more plausible assumptions about firms.

\subsection{Patents}

The preceding discussion has considered the direct gains of innovation - the gains arising to the innovating firm through changes to its own production and emissions. We now extend this analysis to look at how the incentives are altered when firms consider their ability to appropriate some of the social gains of their innovations.

Milliman and Prince (1989) were early to note the difference between patented and unpatented innovations in this context. They model patents in a very simple way: if there are $N$ identical firms in the industry that are subject to a price price on emissions, the innovating firm simply gets a share $s \in[0,1]$ of industry-wide non-innovator gains. Thus, the incentive to develop and adopt technology $i$ provided by the price on emissions is just

$$
\Phi_{i}+s \Phi_{i}(N-1)
$$

Notice that, with patents, the overall incentive to innovate is increasing in the size of the market for the innovation, $N$. Even if the innovating firm is not itself an emitter and does not have to pay for its own emissions, the emissions price nevertheless does affect its incentive to develop abatement technologies. Instead of equation 7 we would simply have $s \Phi_{i} N$.

Fischer et al. (2003) give more structure to the benefits from patents. They consider an end-of-pipe innovation that increases $\alpha$ from $\alpha_{0}$ to $\alpha_{E O P}$, though the analysis that follows can equally be applied to any other type of innovation. The innovating firm gets a patent for this end-of-pipe innovation. Other firms can adopt this new innovation, but would need to pay a license fee of to the innovator. If all other firms adopt the new innovation, we get equation 7 . However, the other firms also have the option to adopt 
an imitation technology $\sigma$ with effectiveness $\alpha_{\sigma}=\sigma \alpha_{E O P}+(1-\sigma) \alpha_{0}$, with $\sigma \in[0,1]$. Note that when $\sigma=1$, the innovation is a pure public good, and any firm can copy the inventor at no cost. When $\sigma=0$, on the other hand, the innovation is a pure private good, and no imitation is possible. Figure 9 illustrates the marginal abatement cost curves $f_{0}(e)$ and $f_{E O P}(e)$, as well as $f_{\sigma}(e)$ for some intermediate value of $\sigma$.

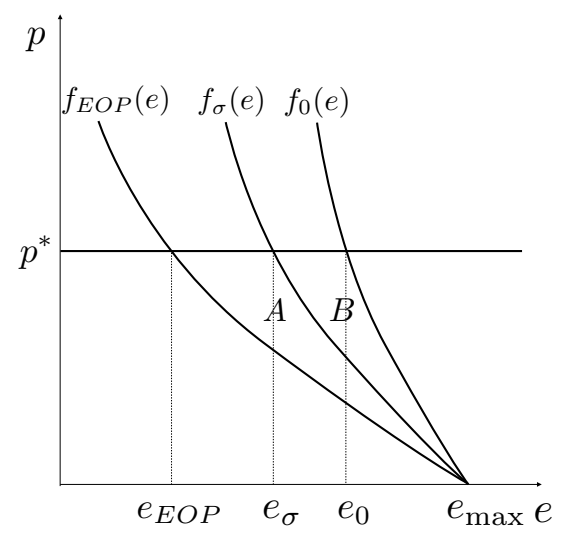

Figure 9: Incentives with patents: The area $A+B$ is the value of adopting the new technology $E O P$, while the smaller area $B$ is the value of adopting the imitation technology $\sigma$. The difference, area $A$, is the additional benefit of adopting the new technology over and above the imitation.

As long as the innovating firm charges a license fee that is no larger than the area $A$ in figure 9 , other firms would prefer to license rather than imitate. The optimal license fee at a given emissions price is therefore a share of the gain from adoption, $s \Phi_{i}$, where $s$ is optimally set to $s=\frac{\operatorname{area} A}{\operatorname{area} A+B}$, so that other firms are just indifferent between licensing and imitating. This provides an economic rationale for the parameter $s$, and $s \Phi_{i}$ in equation 7 can now be interpreted as the license fee charged by the innovator. In this view, $s$ is a decreasing function of the appropriability of the gains from adoption, $\sigma$.

When the price on emissions is set with a tax, diffusion of the technology always increases the gains to the innovator. As we saw in section 3.1, however, when the price is determined in a permit market, adoption of an emissions-reducing innovation causes the price of emissions falls (Fischer et al., 2003; Scotchmer, 2010). In this case the potential gains from adoption are smaller, which means that the the license fees that the innovating firm can extract are smaller. The innovator is thus a classic monopolist, choosing between technology diffusion and extracting higher license fees. The implication is that the innovator may prefer to limit diffusion of the new technology, especially if there is no good imitation technology ( $\sigma$ close to one), and especially if the innovation causes a substantial reduction in the optimal emissions level (the technology represents 
a large increase in $\alpha$ here). Notice that these are precisely the circumstances in which the social cost of limiting the diffusion would be particularly great.

Scotchmer (2010) further notes that when the permit price falls, the optimal level of output will increase for non-adopters (and it will not decrease for the adopters). If demand for the output is inelastic (another situation where where the social cost of limiting diffusion is high), this expansion of output will reduce the innovating firm's profits. In addition to a decline in the license fees the innovating firm can charge, therefore, technology diffusion causes a drop in sales revenues, providing a double disincentive for technology diffusion.

These concerns do not arise with an emissions tax, but with permit markets the innovating firm has excessive incentives to limit the diffusion of abatement technologies. Regrettably, these incentives are strongest when the social costs of limiting diffusion are greatest. This suggests a need for complementary policies to promote diffusion of patented abatement technologies.

\subsection{Optimal policy adjustment}

As our final extension we consider the possibility that the regulator sets a price on emissions with some expectation of firm's technology choices, and may in some cases wish to revise the price once it can observe actual technology choices. This provides firms with yet another opportunity to make strategic technology choices in order to affect the price on emissions.

The most frequently discussed version of this problem was first considered by Milliman and Prince (1989). ${ }^{10}$ Once firms adopt new technologies and shift the marginal abatement cost curve, the price on emissions may no longer be equal to the marginal damage from emissions. If the emissions price or permit quota had initially been set to equate marginal damages and marginal abatement costs, a welfare maximising regulator would now have an incentive to adjust the emissions tax or permit quota in order to realign marginal damages and the emissions price.

For convenience, let us assume that the marginal damages from emissions are increasing in emissions. Additionally, purely so that we can draw the firm's marginal abatement cost curve and the marginal damage curve in the same graph (see figure 10) we assume that there is only a single emitter. ${ }^{11}$ Now, once the emitter adopts an

\footnotetext{
${ }^{10}$ More recent discussions include Kennedy and Laplante (1995, 1999), Mash et al. (2003), and Requate (2005).

${ }^{11}$ In order not to overcomplicate matters, this emitter is still assumed to act as a price-taker in a permit market. This allows us to isolate the effects arising from the optimal policy adjustment. All of
} 
emissions-reducing innovation, causing a shift in the (aggregate) marginal abatement cost curve, the marginal damages from emissions will no longer equal the price on emissions, whether that price is set by a tax or permit quota. To see this, consider figure 10. The marginal abatement cost curve with the initial technology is $f_{0}(e)$, and the regulator has set an optimal emissions tax $p^{*}$ that induces a level of emissions $\bar{e}$. Adopting technology $i$ shifts the marginal abatement cost curve to $f_{i}(e)$, and the firm would now choose to emit $e^{\prime}$. The gain from innovation, as we have seen before, would be $A+\ldots+G$. Note, however, that the emissions price $p^{*}$ exceeds the marginal damages at this level of emissions. With the new technology, the optimal emissions tax is $p^{\prime \prime}$ and optimal emissions are $\bar{e}^{\prime \prime}$. For a permit market, the initially optimal emissions cap is $\bar{e}$, resulting in an equilibrium permit price $p^{*}$. Technology adoption causes a drop in the permit price to $p^{\prime}$, which is below the new optimal permit price $p^{\prime \prime}$. By the same argument as in section 3.1, for a firm that expects the permit price to drop to $p^{\prime}$ the incentive to innovate is $A$. The new optimal permit quota is $\bar{e}^{\prime \prime}$ and optimal emissions are $p^{\prime \prime}$.

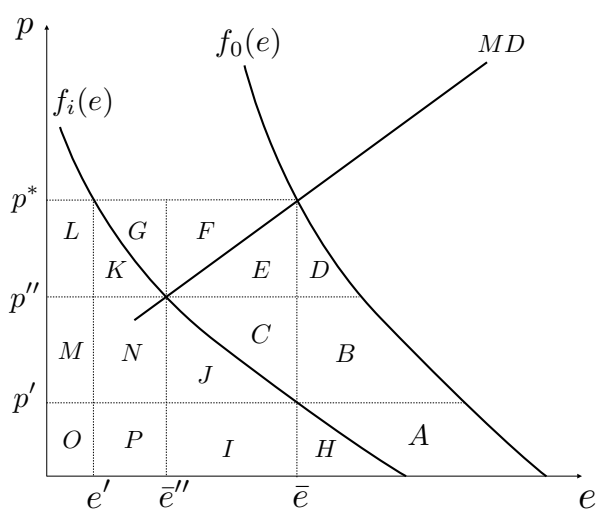

Figure 10: Incentives for Innovation for 'regulation-takers' and 'regulationsetters':

Hence, technology adoption would cause a welfare maximising regulator want to lower the emissions tax, something emitters are likely to welcome. With a permit market, however, technology adoption would cause the regulator to restrict the permit quota, most likely opposed by emitters. Milliman and Prince (1989) further speculated that firms would anticipate the regulator's optimal reduction of the emissions tax, or tightening of the permit quota, which would modify their incentives to invest in the first place.

the analysis in this section can be performed with a monopolist or under imperfect competition, but the effect of optimal policy adjustment will become confounded with other effects. 
To see what happens to the firm's incentives, imagine first that the firm correctly anticipates the new regulations but does not believe it has any power to influence the regulator - the firm is a 'regulation-taker'. The firm knows that the regulator will adjust the emissions tax from $p^{*}$ to $p^{\prime \prime}$ in figure 10. In the absence of regulatory adjustment, the gain from technology adoption is $A+\ldots+G$, while it is only $A+B+C$ with optimal adjustment (by the same argument as in section 3.1). Hence, optimal adjustment of an emissions tax reduces the incentives to invest. The opposite is true of a permit market. The regulator would optimally adjust the emissions cap from $\bar{e}$ to $\bar{e}^{\prime \prime}$, resulting in a permit price of $p^{\prime \prime}$. Without intervention to restrict the emissions cap, however, the price would have fallen to $p^{\prime}$. The gain from switching technology is therefore $A+B+C$ with optimal policy adjustment, as opposed to just $A$. Thus, contrary to an emissions tax, optimal policy adjustment increases the incentives to invest under a permit market where participants are 'regulation-takers'. Notably, with optimal policy adjustment, the incentives for innovation are the same under both an emissions tax and permit market.

Imagine now that the firm is not a 'regulation-taker'. In fact, let us suppose the firm knows that the regulator's decision is entirely contingent on the firm's technology choice - the firm is effectively a 'regulation-setter'. ${ }^{12}$ Under an emissions tax with no adjustment, the incentive to innovate is $A+\ldots+G$, as before. A regulation-setting firm will realise, however, that if it adopts technology $i$ the regulator would lower the tax rate to $p^{\prime \prime}$. As a consequence, the firm would optimally increase emissions to $\bar{e}^{\prime \prime}$, which reduces their abatement costs by $K+N+L$ but increases their tax receipts by $M+N+O+P-L$ at the new tax rate. Thus, in addition to the the area $A+\ldots+G$, the 'regulation-setter' also expects a gain of $K+L$. Optimal tax adjustment therefore increases the incentives for innovation for a 'regulation-setter', opposite to its effect on the incentives of the 'regulation-taker'. In a permit market, the cost-savings to the firm would be equal to the area $A$ without adjustment. However, the regulator would optimally cancel some of the firm's allowances, forcing it to reduce emissions to $\bar{e}^{\prime \prime}$ at a cost $I+J$. The resulting incentive to innovate is only $A-I-J$ (plus any compensation that the firm may obtain for the permits it has lost). Optimal adjustment thus reduces the incentive to invest in a permit market when the firm is a 'regulation-setter', the opposite of the effect on the incentives of a 'regulation-taker'. Table 2 summarises our conclusions thus far.

We have considered two extreme situations - one where the firm is a 'regulationtaker' and one where the firm is a 'regulation-setter'. For the many intermediary cases, the effect of optimal adjustment on the incentives to innovate is not clearly signed.

\footnotetext{
${ }^{12}$ The analysis of this scenario extends a discussion in Kennedy and Laplante (1999).
} 


\begin{tabular}{|l|cc|}
\hline & 'Regulation-taker' & 'Regulation-setter' \\
\hline Emissions tax & Lower & Higher \\
Permit market & Higher & Lower \\
\hline
\end{tabular}

Table 2: The effects of optimal policy adjustment on the incentives of 'regulation-takers' and 'regulation setters'

However, one would expect that the more influence a firm's technology choices has on the regulator's decisions, the greater is the additional incentive to invest provided under a tax, and the greater is the disincentive to invest in a permit market. ${ }^{13}$ This suggests that the choice of instrument will affect who innovates. When emitters expect this kind of optimal policy adjustment, an emissions tax will provide stronger incentives for investment for powerful firms that believe they can influence policy, but provide weaker incentives for less influential emitters. A permit market reverses this relationship, providing stronger incentives to the less influential. Thus, we would expect optimal adjustment of an emissions tax to strengthen incentives for innovation when emissions are concentrated among a few large firms, while optimal adjustment of a permit quota would strengthen incentives when emissions are distributed among a large number of small firms. This provides us with some guidance on the question of choosing an emissions tax or a permit market when the regulator cannot credibly commit to a future policy.

On a broader note, the regulator may well have other objectives in mind than to equate marginal abatement costs and marginal damages, say, to raise revenue. The regulator will still have an incentive to adjust the tax or permit quota, albeit for different reasons. If investments by firms reduces the elasticity of the tax base, the optimal tax rate for revenue raising (i.e. the Ramsey tax) increases (Marsiliani and Renstrom, 2000). The regulator will then have an incentive to raise the tax once firms have invested in a new abatement technology. In terms of our typology of innovations, it is easy to see that, for instance, $P 1$-innovations reduce the emissions price elasticity of emissions, and would cause the regulator to increase a revenue raising emissions tax. The same argument can be made for an permit market, where, if permits are auctioned to raise revenue, the regulator would have an incentive to tighten the cap once firms have invested in abatement technologies. In contrast to the 'equating marginal abatement costs and marginal damages'-motivation, the regulator will have an incentive to make both an emissions tax and an permit quota more stringent. Consequently, optimal policy adjustment will

\footnotetext{
${ }^{13}$ For a more extensive treatment of the impact of this type of optimal policy adjustment on incentives for innovation and investment, see Requate and Unold (2003) and Requate (2005).
} 
in this case reduce the incentives for innovation that reduce the emissions price elasticity of emissions. The opposite applies to innovations that reduce the emissions price elasticity of emissions, such as end-of-pipe and replacement innovations. In this case, the regulator would have an incentive to lower the tax rate, or relax the emissions cap. Consequently, optimal policy adjustment will increase the incentives for these types of abatement technologies.

There are two main things to note here. Firstly, there is no strict correspondence between the direction of change in the emissions price elasticity of emissions and whether the innovation is emissions-reducing or emissions-increasing. A revenue raising tax or permit auction might therefore provide incentives for either or both of these types of innovations. Secondly, the choice of a tax or permit auction does not seem to be very important for the incentives to innovate if the regulator's purpose is just to raise revenue. This highlights the fact that depending on the regulator's objective function, different events will trigger adjustments in different directions. There are many further possibilities not considered here. For instance, Helm et al. (2003) consider a scenario where the regulator has an incentive to weaken the emissions cap (or lower the tax rate) once investments have taken place in order to improve international competitiveness of exporting sectors. (Abrego and Perroni, 2002) examine a situation where the regulator has distributional objectives. Taxes, as well as grandfathered permits, are likely to be regressive with regards to income. Once income becomes more unevenly distributed, the regulator will have a greater incentive to lower the tax rate or weaken the emissions cap in order to reduce the adverse distributional impact.

It is easy to get lost in the intricacies of optimal policy adjustment, and difficult to draw general conclusions about how it impacts the incentives for innovation. If the regulator's objective is to equate marginal abatement costs and marginal damages, optimal policy adjustment weakens the incentives to invest in emissions-reducing innovations for 'regulation-takers' under a emissions tax, but strengthens them under a permit market. The reverse applies to 'regulation-setters'. If the emissions price is primarily a revenue raising tool, however, the effect of optimal policy adjustment on the incentives for emissions-reducing innovation is unclear, and it may even encourage investment in emissions-increasing innovations. The only conclusion to draw is that our model is able to accommodate a number of different characterisations of this problem that appear in the literature. In addition, this simple framework has allowed us to elaborate on the ideas in the literature and further contribute to the understanding of how optimal policy adjustment affects the incentives for innovation. 


\section{Conclusion}

This paper has examined the relationship between market-based instruments and firms' optimal technology choices. The simple model presented in section 2 showed how the gains from different types of innovations depend on the price on emissions. One of the more surprising findings here was that, for some types of innovations, the incentive for investment in abatement technologies may actually be decreasing in the price of emissions. This suggests that conventional wisdom that 'higher emissions prices induce more innovation in clean technologies' deserves at the very least some qualification. This conventional wisdom is valid for some types of technologies, and under some market conditions, but the existence of counter-examples makes the policy maker's problem is more difficult.

This finding can potentially change the policy maker's economic calculus. Since a price on emissions effectively raises the marginal cost of production, it will typically induce the firm to restrict output, which may entail a loss of social welfare. The social welfare gains from a higher price on emissions (reduced emissions and potentially more innovation) are therefore traded-off with the losses from restricted output (Oates and Strassman, 1984). Interestingly, our discussion of process innovations shows that reducing the price of emissions may in some cases actually increase the incentive for innovation. In such circumstances, a lower emissions price provides the dual benefits of increased incentives for innovation and reduced welfare losses from restrictions of output. The practical importance of these cases, however, remains an empirical matter.

It is also important to acknowledge that, although our discussion assumed a profit maximising firm, incentives for minimising costs are present in a number of different managerial models, including Williamson's model of utility-maximising managers (Williamson, 1963) and Niskanen's model of bureaucracies (Niskanen, 1977). ${ }^{14}$ Therefore, even if our algebraic expressions do not reflect all of the forces at work, they are still likely to capture some of the key determinants of the incentives to invest.

Another important feature of our analysis was to represent the firm's problem as one of technology choice. Most of the literature cited in this paper considers the firm's problem as one of deciding whether or how much to invest in a given technologya single alternative technology or a one-dimensional continuum of technologies. Our framework allows us to consider the choice between technologies that can vary along several dimensions. This is a much more faithful representation of the firm's actual decision problem, and emphasizes that a changing price of emissions alters the relative

\footnotetext{
${ }^{14}$ See Oates and Strassman, 1984 for a discussion.
} 
incentives for adopting different types of abatement technologies. This point must be considered very carefully when designing economy-wide emissions regulations, such as in the case of climate policy, since there are different technological opportunities for abatement in different sectors of the economy. The technology choice formulation is more flexible and yields a much richer understanding how the price on emissions influences the firm's innovation and investment decisions, yet remains a tractable alternative for modeling.

Section 3 introduced several extensions of the analysis. When the analysis is extended in these directions, the form of the price (tax or permits), the allocation of emissions rights, the ability to protect innovations from imitation, and the regulator's objectives all become important factors in the firm's technology choice problem. From the policy maker's perspective, this means that any price on emissions invariably favours some abatement technologies over others, or some firms over others, however the price is set. There is no such thing as setting the price and leaving market forces completely at liberty to choose the best abatement technologies. All emissions regulations affect the direction of technological progress. This should not discourage policy makers, but instead emphasises that the technological side of emissions abatement must always be considered in tandem with the design of the market-based instrument itself. 


\section{References}

Abrego, L. and Perroni, C. (2002). Investment subsidies and time-consistent environmental policy. Oxford Economic Papers, 54(4):617.

Ambec, S., Cohen, M. A., Elgie, S., and Lanoie, P. (2010). The Porter Hypothesis at 20: Can Environmental Regulation Enhance Innovation and Competitiveness? CIRANO Working Papers.

Bauman, Y., Lee, M., and Seeley, K. (2008). Does Technological Innovation Really Reduce Marginal Abatement Costs? Some Theory, Algebraic Evidence, and Policy Implications. Environmental and Resource Economics, 40(4):507-527.

Cramton, P. and Kerr, S. (2002). Tradeable carbon permit auctions: How and why to auction not grandfather. Energy Policy, 30(4):333-345.

Downing, P. B. and White, L. J. (1986). Innovation in pollution control. J. Environ. Econ. Manage.;(United States), 13(1).

Fischer, C., Parry, I. W. H., and Pizer, W. A. (2003). Instrument choice for environmental protection when technological innovation is endogenous. Journal of Environmental Economics and Management, 45(3):523-545.

Hahn, R. W. (1984). Market power and transferable property rights. The Quarterly Journal of Economics, 99(4):753.

Helm, D., Hepburn, C., and Mash, R. (2003). Credible Carbon Policy. Oxf Rev Econ Policy, 19(3):438-450.

Kennedy, P. W. and Laplante, B. (1995). Equilibrium incentives for adopting cleaner technology under emissions pricing. World.

Kennedy, P. W. and Laplante, B. (1999). Environmental policy and time consistency: emissions taxes and emissions trading. World.

Kneese, A. V. and Schultze, C. (1975). Pollution, Prices, and Public Policy. (Brookings Institution, Washington, DC).

Laffont, J. and Tirole, J. (1996a). Pollution permits and compliance strategies. Journal of Public Economics, 62(1-2):85-125. 
Laffont, J. and Tirole, J. (1996b). Pollution permits and environmental innovation. Journal of Public Economics, 62(1-2):127-140.

Malueg, D. A. (1989). Emission credit trading and the incentive to adopt new pollution abatement technology. Journal of Environmental Economics and Management, 16(1):52-57.

Marsiliani, L. and Renstrom, T. I. (2000). Time inconsistency in environmental policy: tax earmarking as a commitment solution. The Economic Journal, 110(462):123-138.

Mash, R., Helm, D., and Hepburn, C. (2003). Time-inconsistent environmental policy and optimal delegation. Discussion Paper 175, Oxford University Department of Economics.

Milliman, S. R. and Prince, R. (1989). Firm incentives to promote technological change in pollution control. Journal of Environmental Economics and Management, 17(3):247265.

Montero, J. (2002a). Permits, Standards, and Technology Innovation. Journal of Environmental Economics and Management, 44(1):23-44.

Montero, J. P. (2002b). Market structure and environmental innovation. Journal of Applied Economics, 5(2):293-325.

Moreno-Bromberg, S. and Taschini, L. (2011). Pollution Permits, Strategic Trading and Dynamic Technology Adoption. CESifo Working Paper Series, (3399).

Niskanen, W. A. (1977). Bureaucracy $\& 3$ representative government. Aldine De Gruyter.

Oates, W. E. and Strassman, D. L. (1984). Effluent fees and market structure. Journal of Public Economics, 24(1):29-46.

Popp, D. (2010). Innovation and Climate Policy. National Bureau of Economic Research Working Paper Series, No. 15673.

Popp, D., Newell, R., Jaffe, A., and Syracuse, N. (2009). Energy, the environment, and technological change. NBER Working Paper.

Requate, T. (2005). Dynamic incentives by environmental policy instruments-a survey. Ecological economics, 54(2-3):175-195. 
Requate, T. and Unold, W. (2003). Environmental policy incentives to adopt advanced abatement technology: Will the true ranking please stand up? European Economic Review, 47(1):125-146.

Scotchmer, S. (2010). Cap and Trade, Emissions Taxes, and Innovation. NBER Chapters. National Bureau of Economic Research, Inc.

Storrøsten, H. B. (2010). Incentives to invest in abatement technology. A tax versus emissions trading under imperfect competition. Technical report, Research Department of Statistics Norway.

Tietenberg, T. H. (1985). Emissions trading: An exercise in reforming pollution policy. Technical report, Washington DC: Resources for the Future.

Weber, T. A. and Neuhoff, K. (2010). Carbon markets and technological innovation. Journal of Environmental Economics and Management, 60(2):115-132.

Williamson, O. E. (1963). Managerial discretion and business behavior. The American Economic Review, 53(5):1032-1057. 